\title{
Power influences upon technology design for age-related cognitive decline using the VSD framework
}

\begin{abstract}
Implicit in the value sensitive design (VSD) approach is a concern for understanding, and where possible, disrupting problematic power relationships. Yet an awareness of the issues and ethics of power relations is a pre-requisite for such a concern to bear fruit. This article provides some insight into the issues, and through a case study of technology design to support care arrangements for age-related cognitive decline, illustrates how finding a satisfactory resolution can be particularly troublesome.
\end{abstract}

\section{Keywords}

Health informatics, participatory design, philosophical ethics, values, power, value sensitive design.

\section{Introduction}

Value sensitive design (VSD) builds on participatory design, and that body of literature has addressed the issue of power to a significant extent, particularly in relation to employeremployee issues in Scandinavian countries (Bjerknes et al. 1987; Bødker et al. 2000). VSD endeavours to include a broad range of direct and indirect stakeholder roles, those who influence and will be influenced by the processes and outcomes of design. However, VSD has not to date addressed the issue of power, which is seen in the section on grand challenges in this special issue as well. Instead it is assumed that research teams and the organisations will support "doing the right thing", without needing to be explicit about the role and importance of power relationships. Implicit in the VSD approach is a concern for understanding, and where possible, disrupting problematic power relationships. With the exception of a recent dissertation (Agarwal 2015), little has been done to account for power relationships in the design process in relation to VSD, particularly in its application to specific domains, or the power relations inherent in artifacts that have been deployed using VSD. This article addresses part of that challenge by examining power in the domain of technologies for people with age-related cognitive decline.

\section{A philosophical lens: power and technology design}

Brey (2007) has outlined the following framework for a critical understanding of technology's impact upon society and power relations: "A critical theory of this sort requires the development of an answer to four questions: (1) the theoretical question: How can technology play a role in the distribution and exercise of power? (2) the factual question: What is the role of technology in the distribution and exercise of power in contemporary society? (3) the normative question: What role should technology have in the distribution and exercise of power in society? and (4) the practical question: What steps can be taken to move closer to this ideal?" The theoretical, factual and normative questions enable us to develop and envisage "policies and practices for the realization of a society in which technology is a force for empowerment rather than for domination" (Brey 2007).

One approach to the fourth - practical - question gives rise to the practice of VSD. Practitioners of VSD, however, need to be well versed in a range of answers to the first three questions, if they are to avoid simply reinforcing power structures within society that may run counter to the "human well-being; human dignity (respect); justice; welfare...; human rights ...; and freedom" (Burmeister et al. 2011) that VSD hopes to promote. As Brey continues, "The preliminary answer to the normative question is... that the role of technology should be such that it aids in the arrangement of power so that the ideals of democracy, freedom and 
justice are attained as well as possible" (Brey 2007). Assuming that "power relations are both established by the actions of agents and by the workings of social structures" (Brey 2007) it is important to note that, "although power relations do not require intentionality, the exercise of power always does" (Brey 2007). Such exercise, moreover, is often opaque, and more complex than it may at first seem. Take, for example, Bentham's famous panopticon - "the circular prison building that allows guards to observe all prisoners without being observed themselves," (Brey 2007) - with which Foucault illustrates his notion of disciplinarity. As a prison, the exercise of power is relatively transparent. As an image for modernity it implies technologies of surveillance that can impose behavioural conformity in more subtle ways. Here, power is exercised upon the surveilled in a network of power relations that promotes an "inner policeman," ensuring behavioural conformity is self-policed, rather than directly imposed. Yet in some cases - for example with CCTV in town centres - such surveillance can be widely welcomed rather than resisted. More Gramscian, hegemonic power relations, therefore, whereby the ruled welcome the restrictions imposed by their rulers because those restrictions are clothed in ways attractive to the ruled, can thus be implicit in the workings of many social structures as well as being the result of deliberate actions by agents among ruling classes (Kreps 2015). These issues can present difficult questions practitioners of VSD should be able to navigate with sensitivity, as our case study, below, exemplifies.

\section{VSD and the domain of age-related cognitive declines}

VSD is a design framework that focuses attention on the interaction between stakeholders and technology artefacts, through a consideration of social and moral values (Friedman et al. 2006; Davis \& Nathan 2014). Although VSD has been applied in many domains, only a few VSD studies have been conducted in the domain of technology design involving people with age-related cognitive decline (Teipel et al. 2016; Burmeister 2016, 2010; Sharkey 2014; Schikhof et al. 2010; Fitzpatrick et al. 2015). Fitzpatrick et al. (2015, p 18) also recommend that in this area "rigorous ethical reflection" is required to complement the application of VSD. Our present reflection on ethical notions of power is an attempt, in part, to address this need, as was the recent work of Kreps et al. (2016), which explored the design of technology artefacts (not using VSD) for people with age-related cognitive declines, through the interpretive lens of notions of personhood, recommending the incorporation of skeuomorphs - a form of design latency - in technological development.

Values aid our understanding of what is desirable, good or worthwhile in life. They imply expectations about behaviour. VSD is a form of social engineering, and as such needs to address power considerations in a rigorous manner. If Value Sensitive Designers simply assume that stakeholders will act in the right way to ensure equity, then they may also be assuming that stakeholders a) agree that equity is an aim, b) know what is "the right way" to ensure equity in the first place (if there even is one), and c) that those stakeholders are willing to give up their power position (and are aware that they hold a power position). Stakeholders with cognitive declines present even more complex problems. VSD needs to ensure that technology can be an integrated part of a good life, by matching and enhancing, rather than disrupting, key values that guide our pursuits in daily life - even if that means disrupting power relations that are obstacles to such enhancement.

\section{Case study of power considerations in the application of VSD}

Defined loosely as a disorder of the mental processes marked by problems with memory, personality changes, and impaired reasoning, dementia is a spectrum of age-related cognitive declines. The following case study serves to illustrate the application of VSD in the domain 
of technology for people with age-related cognitive decline. Power is, in this case study, both extended in the design process, and, thereby, mitigated in the deployed artifact.

Assistive technologies in general are increasingly pervasive, in hospital wards and patients' homes, presenting new challenges to design, and complex power relations. Schikhof et. al. (2010) describe a case which explores the role of monitoring systems in small-scale housing for older people with dementia, by firstly trialling one in a nursing home. Significantly, this project extended power to the residents of the nursing home by including them, alongside the technology designers and the clinicians, as stakeholders in the VSD process. By incorporating principles of value-sensitive design in this way they then developed a more humane system for remote monitoring at night in dementia care.

The aim of the system was to address high staff workloads by implementing infrared sensors "to alert staff in case a psycho-geriatric patient with a risk of falling, gets out of bed and needs assistance. The frequency of false positive alarms, however, costs valuable time of staff due to the large working area and may cause alarm fatigue" (Schikhof et al. 2010, p 411). One night duty staff member was responsible for 30 residents, and when the project moved to small scale housing, one staff member would be responsible for 27 residents in four separate living units. Clinicians were concerned with safety and wanted continuous monitoring, whereas residents were concerned to keep intrusions of their privacy to a minimum.

Through its resolution of the varied value tensions between stakeholders, the study serves as an illustration of power considerations in the design process. Using the VSD approach the assistive technology they designed allowed a resident to enjoy the privacy they desired until a motion sensor indicated that they were going to rise from their bed. At that point a sensor alarm activated and sent live video to the portable device of the staff member on night duty, who could then make a professional judgment about the safety of the resident and whether assistance was required. The panoptic surveillance involved, as with CCTV in town centres, was seen as something that would be welcomed, and the mobile live video the best and most immediate technological support for the busy staff member. The intrusive power relation imposing behavioural conformity implicit in the live video feed was regarded as a necessary price for patient safety; but it was only triggered when the patient rose from their bed, demonstrating sensitivity to patient privacy incorporated into the design of the system. Whether this system found the optimum resolution to the competing needs of patient privacy, patient safety, and the paucity of staff time, remains open to discussion; that it made some effort toward a resolution, is testimony to the power of VSD.

In considering power relationships, of course, one has to note, as with all user-centered design, that the users, whilst central to the design process, are merely participants or codesigners in that process, and not the technological designers themselves. Power is exerted, furthermore, not only by those technicians, but by the management of the aged-care facility, and through legislative obligations which society as a whole imposes on professional caregivers. Technology design, therefore, is only one element of this process, and often has a limited ability to influence power structures. As seen in this example, safety was particularly a concern for professional caregivers and management of the aged-care facility. Designers therefore sought to increase monitoring/surveillance as a way to achieve safety. However, the participation - and empowering - of patients in the design process was critical for capturing further design constraints: concern for patient autonomy, which is frequently associated with, but not limited to notions of independence, resulted in the trigger system, rather than 
permanent surveillance, making the final deployed artefact more limited in its power relation over the surveilled.

This case, then, serves as a good example that VSD needs always to be clear about the exercise of power. For the technological designer, it should always be as intentional as possible. Rather than allowing power to be exercised in an intuitive or unconscious manner, VSD processes should be fully cognisant of the potential traps of the politics of artefacts (Winner 1986). "Technology," Brey reminds us "can help agents exercise power over others by either giving them new powers or by improving the efficiency, effectiveness, reliability and ease by which existing powers are exercised" (Brey 2007). For Winner, technology is infused with politics; it is at the very least politics by other means. Technological artefacts, for Winner, are often nothing less than objects created to "enhance the power, authority, and privilege of some over others" (Winner 1986) exemplifying Brey's 'power over,' as opposed to 'power to,' whereby power is exercised for the control of others, rather than as a personal empowerment towards achievement. As evidenced in the case study, above, VSD needs at times to navigate very complex interfaces between sometimes competing pressures, and be prepared to reach sometimes uncomfortable compromises where the requirements of social structures (power over the process) constrain the scope of design (power to influence relations). Nonetheless, as we hope we have shown in this article, an awareness of power relations amongst practitioners of VSD is key to approaching a satisfactory compromise, however uncomfortable, if VSD is to achieve even micro-steps of progress towards "the realization of a society in which technology is a force for empowerment rather than for domination" (Brey 2007).

\section{Conclusion}

One aim of systems engineering is to design technology such that it is better than what would have been achieved without the application of evidence-based engineering principles. However, in what ways it is better - and for whom - has yet to be determined. In this article the focus has been on 'better' in terms of designs that more democratically address power imbalances.

VSD needs a critical understanding of technology's impact upon society, and to be clear whether it is either (a) making 'inherently political technologies' that promote disempowering social power structures more socially acceptable and accessible, or (b) contributing to technologies that aid the "arrangement of power so that the ideals of democracy, freedom and justice are attained as well as possible" (Brey 2007).

\section{References}

Agarwal, S. D. (2015). The Process of Networked Civic Innovation: Examining the Role of Values, Resources, and Power in Community-Based Technology Projects. PhD, University of Washington, Seattle, USA.

Bjerknes, G., Ehn, P., \& Kyng, M. (Eds.). (1987). Computers and Democracy: A Scandinavian Challenge: Avebury.

Bødker, S., Ehn, P., Sjögren, D., \& Sundblad, Y. Co-operative Design - perspectives on 20 years with 'the Scandinavian IT Design Model. In NordiCHI 2000, 2000

Brey, P. (2007). The Technological Construction of Social Power. Social Epistemology, 22(1), 71-95.

Burmeister, O. K. (2010). Websites for seniors: Cognitive accessibility. International Journal of Emerging Technologies and Society, 8(2), 99-113. 
Burmeister, O. K. (2016). The development of assistive dementia technology that accounts for the values of those affected by its use. Ethics and Information Technology, 18(3), 185-198, doi:10.1007/s10676-016-9404-2.

Burmeister, O. K., Weckert, J., \& Williamson, K. (2011). Seniors extend understanding of what constitutes universal values. Journal of Information, Communication \& Ethics in Society, 9(4), 238-252, doi:10.1108/14779961111191048.

Davis, J., \& Nathan, L. P. (2014). Value sensitive design: Applications, adaptations, and critiques. In J. van den Hoven, P. E. Vermaas, \& I. van de Poel (Eds.), Handbook of Ethics, Values, and Technological Design (pp. 1-26).

Fitzpatrick, G., Huldtgren, A., Malmborg, L., Harley, D., \& Ijsselsteijn, W. (2015). Design for Agency, Adaptivity and Reciprocity: Reimagining AAL and Telecare Agendas. In V. Wulf, K. Schmidt, \& D. Randall (Eds.), Designing Socially Embedded Technologies in the Real-World (pp. 305-338). London: Springer London.

Friedman, B., Kahn, P. H., Jr., and Borning, A. (2006). Value Sensitive Design and Information Systems. In P. Zhang and D. Galletta (eds.), Human-computer interaction in management information systems: Foundations (pp. 348-372). Armonk, NY: M. E. Sharpe.

Kreps, D. (Ed.). (2015). Gramsci and Foucault: A Reassessment. Farnham: Ashgate Publishing.

Kreps, D., Burmeister, O. K., \& Blaynee, J. (2016). Skeuomorphic Reassurance: Personhood and Dementia. In D. Kreps, G. Fletcher, \& M. Griffiths (Eds.), Technology and Intimacy: Choice or Coercion: 12th IFIP TC 9 International Conference on Human Choice and Computers, HCC12 2016, Salford, UK, September 7-9, 2016, Proceedings (pp. 61-71). Cham: Springer International Publishing.

Schikhof, Y., Mulder, I., \& Choenni, S. (2010). Who will watch (over) me? Humane monitoring in dementia care. International Journal of Human-Computer Studies, 68(6), 410-422, doi:10.1016/j.ijhcs.2010.02.002.

Sharkey, A. J. C. (2014). Robots and Human Dignity: the effects of robot care on the dignity of older people. Ethics and Information Technology, 16(1), 53-75, doi:10.1007/s10676-014-9338-5.

Teipel, S., Babiloni, C., Hoey, J., Kaye, J., Kirste, T., \& Burmeister, O. K. (2016). Information and communication technology solutions for outdoor navigation in dementia. Alzheimer's \& Dementia: The Journal of the Alzheimer's Association, 12(6), 695-707, doi:10.1016/j.jalz.2015.11.003.

Winner, L. (1986). The whale and the reactor: A search for limits in an age of high technology. Chicago, USA: The University of Chicago Press. 